This is an electronic reprint of the original article. This reprint may differ from the original in pagination and typographic detail.

Author(s): Rousi, Rebekah; Leikas, Jaana

Title: Life-Based Design as an extension of problem-based learning : a tool for understanding people and technology

Year: $\quad 2015$

Version:

Please cite the original version:

Rousi, R., \& Leikas, J. (2015). Life-Based Design as an extension of problem-based learning : a tool for understanding people and technology. In Proceedings of the Frontiers in Education 2015 : Launching a New Vision in Engineering Education (pp. 1125-1132). IEEE. Conference proceedings : Frontiers in Education Conference. https://doi.org/10.1109/FIE.2015.7344209

All material supplied via JYX is protected by copyright and other intellectual property rights, and duplication or sale of all or part of any of the repository collections is not permitted, except that material may be duplicated by you for your research use or educational purposes in electronic or print form. You must obtain permission for any other use. Electronic or print copies may not be offered, whether for sale or otherwise to anyone who is not an authorised user. 


\section{Life-Based Design as an extension of problem-based learning - a tool for understanding people and technology}

\author{
Rebekah Rousi \\ Department of Computer Science and Information Systems \\ University of Jyväskylä \\ Finland \\ rebekah.rousi@jyu.fi
}

\author{
Jaana Leikas \\ VTT Technical Research Centre of Finland Ltd \\ Finland \\ jaana.leikas@vtt.fi
}

\begin{abstract}
Global conditions are changing at such a rate that foreseeing trends in technological development, economic fluctuations and climatic conditions is ever more difficult. When developing technologies, there is one constant factor that practitioners and researchers should be aware of, and that is people. This is not to say that people, culture and social conditions remain stagnant, for these too evolve with the surrounding circumstances. Rather, appropriate tools and capabilities for investigating people, their lives and life situations, are integral to understanding what people need in terms of technology, how these technologies will be used, and more importantly how they will be valued in the scheme of a person's life. This paper describes the process and outcomes of a course in Cognitive Science focused on developing the tools needed for Life-Based Service Design (LBSD). The course is implemented via problem-based learning (PBL), and students are guided through the process by charting an explanatory method adhering to the Life-Based Design (LBD) ontology. This ontology comprises: 1) Form-of-life analysis; 2) service concept and requirements; 3) fit-for-life analysis; and 4) innovation design. Results show heightened awareness and sensitivity of life conditions, values and needs, revealing design concept strengths and weaknesses in the pre-development phase.
\end{abstract}

Keywords-life-based design; problem-based learning; cognitive science; service design; interaction design

\section{INTRODUCTION}

In the world of education there has been much discussion on the need to train students in $21^{\text {st }}$ century skills [1] [2] [3]. Despite attempts to establish frameworks [2], the term $21^{\text {st }}$ century skills often remains vague as a concept, especially in terms of substance. There is no prescribed set of skills that will prepare individuals for the $21^{\text {st }}$ century [1]. However, Trilling and Fadel [2] identify that the century will require several skill sets. These include: 1) learning and innovation skills - critical thinking and problem solving, communication and collaboration, creativity and innovation; 2) digital literacy skills - information, media and ICT literacies; and 3) career and life skills - flexibility and adaptability, initiative and self- direction, social and cross-cultural interaction, productivity and accountability, as well as leadership and responsibility.

While we are pointed to the direction of what types of skills need to be instilled and developed, the exact skills and tools needed remain vague. This vagueness lies in our inability to adequately predict the vast changes that are expected to occur over the next 20 to 30 years in relation to climate, technology, social, economic, cultural and other conditions that a wait. In fact, the dependence of our livelihood and wellbeing, physically, socially, psychologically and financially on radically developing technological conditions, means that we are quite often only able to rely on the state of things today, rather than count on what comes tomorrow.

For this reason, in the Cognitive Science education program, the university has introduced the Life-Based Service Design course. While we cannot fully imagine the possibilities of tomorrow on the basis of technology, we can direct students towards the source of these developments - people. People are diverse, not only amongst one another, but also within themselves. Due to continual physical and psychological life processes of cell generation and cell death, learning and experiencing, human beings are never the same entity from one moment to the next [4] [5]. This is why overlooking people and focusing on aspects such as technology, and other designed systems, leaves us prone to a lack of understanding regarding how these systems develop and operate.

In this paper we describe the Life-Based Design (LBD) methodology, and how it serves to gauge the nuances of human cognition from the perspective of life circumstances, or as termed in LBD, Forms of Life (FoLs) [6]. We then go on to describe problem-based learning (PBL) and how it is integrated into LBD as not only an approach to design practice, but also as a method for learning about human cognition, its relationship to physical reality, and how this impacts (or should impact) the way practitioners approach 
service and system design. The paper moves on to describe how the LBSD course has been implemented over the past two years (2013 and 2014), what processes students undergo, how they choose topics, gain mentoring, and reflect these learning processes. The learning outcomes of the course are then described in terms of subsequent projects students have endeavored as well as resulting services. In the conclusion we discuss the effectiveness of the course, and directions for future LBSD problem-based learning.

\section{LIFE-BASED DESIGN METHODOLOGY}

The main tenet of LBD is that services and technology should exist for the benefit of life quality [6] [7] [8]. The four main phases of LBD methodology are: Form-of-life (FoL) analysis, concept design, fit-for-life design (FfL), as well as innovation design [8]. LBD differs from other humantechnology interaction (HTI) design paradigms, which include human factors, usability engineering, and ergonomics in that these paradigms focus on the systems and services themselves. That is, according to Leikas et al. [8] they are devoted to establishing seamless and unproblematic interactions between people and systems, yet from a technological perspective [9] [10] [11] [12] [13] [14]. Thus, the study of people in these paradigms is focused on the HTI, and how well systems operate in light of the user.

LBD on the other hand, starts from human beings and their life conditions (i.e., family, career, age, gender, socioeconomic, cultural, ethnic, religious, disabilities etc.) and identifies the areas which may be assisted and enhanced by particular technological solutions, in order to improve life quality. The components of LBD can be seen in Figure 1, which illustrates the relationship between FoLs, Rulefollowing actions (RFAs) and Technology-supported actions.

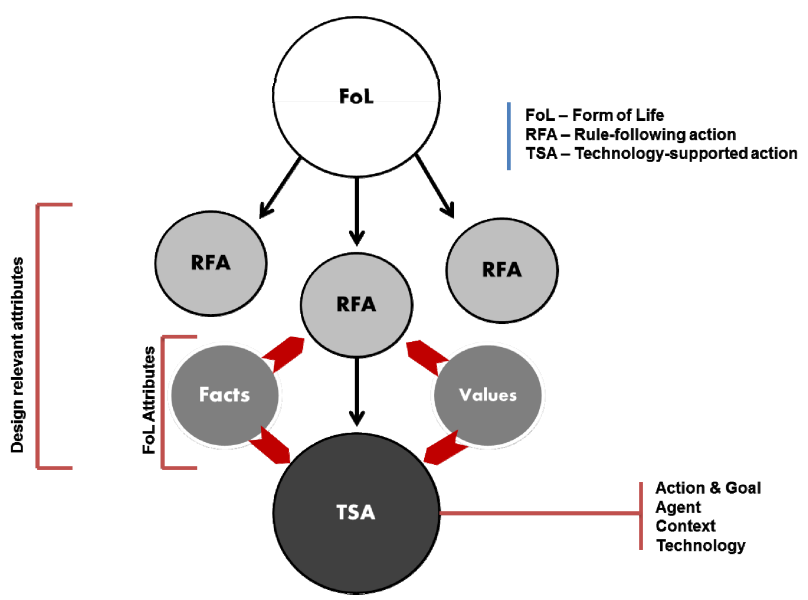

Fig. 1. Components of design leadership according to LBD, adapted from Leikas [6], p. 6.

As stated above, central to the service design process in LBD is the person and their FoL, or life circumstances (physiological, psychological, social, economic, information, etc.). Everyone in their FoL engages in RFAs. That is, similar to routines, people fall into pattern of actions and behavior. These patterns may begin from a necessity, i.e., waking up early to go to work, and then continue even when the actions are no longer necessary (e.g. retirement or while on vacation). Thus, the facts are elements which are inherent to the FoL, such as the need to arrive at work on time, while the values (and norms) possess the meaning of action - why people behave the way they do. Then, the design relevant attributes inform the designer when making specific design decisions for people experiencing the FoL in question. This in turn affects the technology-supported action (TSA), which in itself is the dynamic interaction of action and goal, agent, context, and technology or service. [6]

\section{PROBLEM-BASED LEARNING}

Problem-based learning, or PBL, is a constructivist approach to learning that engages students through the presentation of problems, relevant to the desired learning outcomes in question [15]. It was originally developed by Howard Barrows and colleagues at the McMaster Medical School in 1969, not as a pedagogically or psychologically tried and proven method for learning, but instead as a way of making the learning of medicine fun [15]. While there are many forms and adaptations of PBL, some of the core principles behind the method are: 1) PBL is student-centered; 2) it generally takes place in small groups or teams; 3) learning is active, whereby learners actively seek answers themselves; 4) cases or problems are utilized as stimuli for learning; 5) and learning takes place during independent study time, which is usually significant [16] [17].

PBL has been defined in terms of learning objectives and goals, teaching philosophy, in addition to pedagogical attitudes and values [18]. PBL has even been identified as a 7step process by authors such as Henk G Schmidt [19] who isolated the seven steps as being: 1) the clarification and agreement of 'definitions in progress' of terms and concepts which are as yet, still unclear; 2) identification of the problem(s) in question and agreement of issues and phenomena which need further explanation; 3) the analysis of effects of various components (via e.g. brainstorming) and explanations in order to form a rough hypothesis; 4) the discussion, arrangement and evaluation of likely reasoning facilitating the working hypothesis; 5) creating and ranking learning objectives; 6) undertaking independent research to develop a deeper understanding of these objectives between tutorials or seminars; and 7) the reporting of findings at tutorials and seminars, which thus aids in the establishment of plausible explanations and reapplication of these explanations to new information and problems.

PBL has been characterized in terms of its strengths and weaknesses. In terms of positive cognitive attributes, PBL is noted as promoting better memory retention of material learned during problem-based processes. The applied way in which knowledge is acquired means that this knowledge is more readily recalled and utilized in solving other similar 
problems. Pattern recognition is enhanced and encouraged through knowledge acquisition that occurs over time via real life examples. Further, PBL promotes the activation of prior knowledge which enables efficient processing of new information. Knowledge, or pieces of information, are readily explained and contextualized during moments of learning. Then finally, the attachment of context to knowledge acquisition eases future recall. [15] [20]

The negative aspects of PBL have been characterized as mainly placing too much load on working memory. This is noted by Kirschner, Sweller and Clark [21] as being problematic in that the working memory is incapable of simultaneously problem-solving and learning. In other words, its capacity is said to only enable one of these actions per time. Additionally, Kirschner et al. [21] highlight that processes of learning how to practice in a field of knowledge such as medicine and the processes of actually practicing cognitively differ. We argue that by implementing PBL in the Life-based service design course we not only promote the learning of user-centered design (UCD) modalities in a fun way, but the processes of PBL and the LBD approach to UCD are complimentary, and can be used to reinforce one another.

This is due to the explicit stages of LBD ontology examination and definition which sit neatly with Schmidt's [19] outline of the 7-step approach to problem-based learning. Learners are encouraged to consciously reflect on the learning process, not simply in terms of the LBD methodology itself, but also of the designer's process in coming to understand other individuals (people in various FoLs) and in particular, their cognition. More will be explained about this mutually complimentary process in sections V and VII.

\section{PBL IN DESIGN AND ENGINEERING EDUCATION}

In their article "Engineering education - is problem-based or project-based learning the answer?" Julie Mills and David Treagust [22] criticize the then dominance of "chalk and talk" (p. 2) education. Mills and Treagust highlight the importance of keeping pace with the rapidly changing technological conditions engineers in today's world face. They additionally emphasize the significance of developing skills such as flexibility, adaptability, and most importantly people skills. In particular, they stress research findings which suggest that engineers should possess effective teamwork and communication skills [23] [24]. On this note, Helen Beetham and Rhona Sharpe [25] see PBL as a means of gaining and strengthening $21^{\text {st }}$ century skills precisely for its qualities in supporting collaborative learning and requiring that learners seek the answers themselves - without the guidance of a teacher or tutor. Their argument is that conditions the students find themselves in, such as their technological landscape, should guide the process. With this said, they emphasize that the technology should lead the learning process, rather than traditional teaching and learning methods, limiting the advantages of the technologies.
PBL is noted as being favored among students in that it prepares students for the eventuality that the worlds of engineering and design are problem-based environments [22] [26] [27]. Thus, allowing students to practice problem-solving in the safety of their learning contexts. This is critical when considering the design and engineering professions as solving everyday problems [28]. Furthermore, PBL is quite similar to project-based learning, in that they both require group work and collaboration as well as self-directed learning. Furthermore, both modes are noted for their interdisciplinary natures. However, the difference between the two is that project-based learning is focused on applying knowledge, while PBL is focused on acquiring it [29]. This is where LBD as a method differs from pure PBL in that it requires both acquiring and application during the research process, and in the reporting phase. With PBL as a methodological back drop, the following describes the application of LBD as an extension and practical application of this type of self-directed group approach to learning.

\section{LIFE-BASED SERVICE DESIGN COURSE - IMPLEMENTATION AND LEARNING PROCESSES}

The Life-based service design (LBSD) course has been offered as a course through cognitive science for the past two years. It is an advanced learning module, taught at a master's degree level with the possibilities to continue research cases from differing aspects in other courses held in the program. Due to the time and work demands of lecturers as the result of numerous supervision sessions (or tutorials) during the course, student numbers are kept to a minimum. The course is open to a maximum of 25 students per time, meaning that there are essentially five to ten groups, and thus, cases. While four group members are the maximum, ideally two to three member groups are the optimum size.

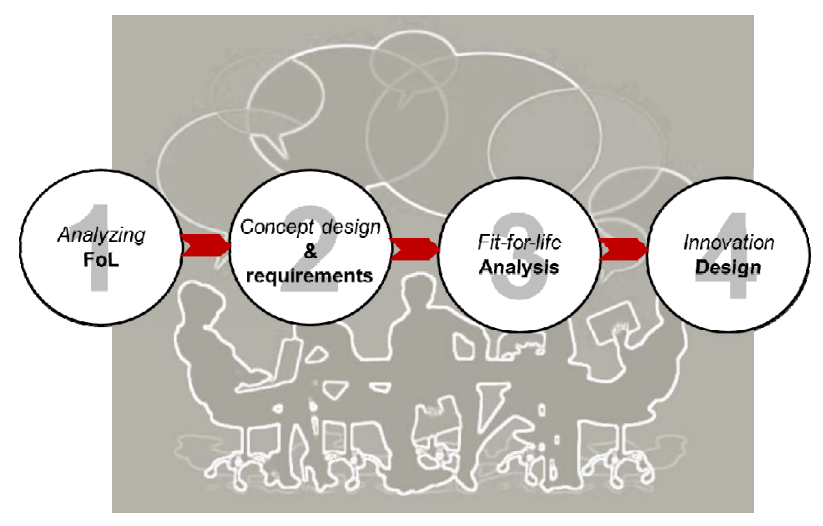

Fig. 2. Stages of the LSBD ontology (see [6])

At the beginning of the course students are provided with information about LBD in the form of two lectures. LBD is introduced firstly as a concept, and then as a design and engineering methodology. The concept is introduced in relation to research which has been undertaken relating to 
technology generations, or gerontechnology [30] [31] [32]. It highlights the fact that in order to become genuinely engaged in $\mathrm{UCD}$, and to essentially truly design for people and their diversity - differing requirements and desires for differing life circumstances - designers and engineers must become familiar with technology and service users on a day-in-the-life basis.

The methodology is explained at the same time as the assignment guidelines are distributed to the group. These guidelines are labeled 'LBSD ontologies', following the ontologies of LBD [8] and comprise four steps: 1) Analyzing forms-of-life; 2) the concept (design) and requirements; 3) Fitfor-life analysis; and 4) innovation design. These steps of the methodology are instrumentally used to break down the assignment task of the course. Each step is outlined as follows. Figure 2 illustrates the stages of the LBSD ontology.

\section{A. LBSD ontologies and learning stages}

\section{1) Analysing forms of life (FoL)}

For this step students, and ultimately designers/engineers, are guided to define the problem area and explore the nature of the FoL (life circumstances) of the service's target users. Through contextualizing and identifying the problem area and human elements involved in the problem, the students are then able to establish a design problem, for example the lack of high speed internet connection for a particular digital learning application at an elementary school in some part of the world. Additionally, what is included in the 'form-of-life analysis' is the discovery of 'Rule following actions' (RFAs). These are typically known as habits which have formed through years of repeated actions, possibly for specific reasons. In an educational context this may be the practice of taking notes in lectures. Although these days students have access to lecture material via online learning platforms such as Moodle, Blackboard and other spaces, for more mature students, the practice of note-taking is upheld, and in many cases assists cognition through the kinetic processing of information [33]. These RFAs are particularly important when not only trying to understand users and potential users, but also when anticipating the use and potential use of the service in question.

Further, logically the actors, or users (teachers, administrators, learners and possibly parents), need to be identified even before commencing the journey of exploring life circumstances and RFAs. These actors need to be identified in terms of age, gender, skills, culture, socialeconomic circumstances, educational level, field, subject and other relevant information.

Then, the typical use contexts need to be established and explored. Information that is required of the context includes social, psychological, physical and technical factors. For instance, when designing digital learning services for mature aged students, designers must be aware of conditions such as technophobia, and possible social stigma surrounding technology such as computers, the internet and distance learning that may be held by a particular group of learners. There are possibilities to overcome these issues via the technical design which may also be enhanced in the way the services are implemented - i.e. via a combination of face-toface and online meetings.

Finally, as a tangible starting point for the service design, students are required to define the design theme and purpose of use. The purpose of use may have been the trigger for the service project, however, through FoL analysis other, previously unforeseen uses may arise, which could be critical to the success of the service.

\section{2) The concept (design) and requirements}

This step, which is quite similar to Schmidt's step 2 in PBL, where the problem in question is determined, focuses on establishing what type of service design concept is to be developed in addition to the user requirements. Yet, rather than concentrating on the service itself, students are encouraged to explore the FoL in relation to RFAs in order to derive what types of technologies are appropriate and have the potential for enhancing quality of life. Thus, RFAs are examined for possible technology and service-supported actions. For example, telephone answering services have been developed with the idea in mind that in certain situations such as meetings, while driving and in other cases people cannot answer the phone. Yet, it is more convenient for the caller to leave a voice message than to independently type an SMS message. Similarly, online shopping - particularly grocery and even fast food ordering - have been developed for people who prefer to avoid crowds or do not have time to pick up goods in person.

At this stage students, and LBSD designers, investigate the possible alternative solution ideas. This is achieved by brainstorming - also prominent in PBL in steps 3 and 4 in particular. During these brainstorms attention is placed on elaborating various solution models - types of services or technologies, and what is required. The interaction between users and services is explored in terms of user-interface prototypes (fast or paper prototypes) and through further discussion.

Ideas and prototypes are tested with real users from the relevant FoLs (target groups). This is achieved both in terms of the conceptual model, and possibly even regarding more specific issues such as usability if the user interface prototype is at such a level of completion that usage can be simulated and/or evaluated. These investigations lead to a more precise definition of the technical solution concept. Thus, the design for development is known by now, and students can set their sights on gauging whether or not the service will suit the FoLs and RFAs in question.

\section{3) Fit-for-life analysis}

The Fit-for-life analysis, or FfL analysis, stage looks at how the FoL may be improved by the inclusion of the service 
in development. This is somewhat of a departure from traditional product and service design in which a market is located through identification of possible uses [34]. Here, focus is placed specifically on how the innovation may potentially improve life quality of those who use it. Thus, emphasis is on the intangible value of the research and design work. This is quite similar to the hypothesis development occurring in PBL (Schmidt). Reflecting the design concept back onto real life situations and pairing the concept and its prototypes with target users' practical everyday life and values students (and designers/ engineers) can re-evaluate as to whether or not the concept is the best solution for the design problem in question.

During the FFL analysis meanings are explored, particularly in terms of what the service design concept means for the FoL under investigation. Meaning is especially pinned to the idea of improving life quality, whether this is in terms of making daily living (actions and chores) easier, or by encouraging happiness through social interactions with peers and loved ones. When considering life-long learning and its increasing popularity, digital and online learning solutions may be a key to improving life quality by enabling learners to become more actively involved in their learning. However, the learning solutions need to match the technologies and capabilities possessed by many mature-aged users.

Finally, during this stage special consideration needs to be given towards ethical questions regarding the user, usage, user context, and of course the service concept design being developed [35]. The service needs to be observed from an ecosystemic perspective which gauges the elements, not simply as separate elements, but as interacting actors, which change in meaning and therefore consequences depending on their combinations.

\section{4) Innovation design}

The final stage of the LBSD and learning process is the innovation design component. It is at this point that the actuality of the service design is considered. Here, matters such as infrastructure and use culture creation are examined. Distribution and sales are strategized in terms of marketing and implementation. Other problems or issues which need to be tackled by the students are for instance maintenance plans (particularly of online services) and the expected life-span.

\section{B. How it works}

The course is structured as to give students a brief introduction to the terms and concepts of the course. They are then initiated into the group assignment via the presentation of FoLs and their associated problems, in addition to already formed cases. For instance, one FoL may be young elderly people (55-75+) who have received an early diagnosis of memory impairment. Another may be mothers of young children seeking activities and play friends for their children. Groups are formed based on the students' interests, i.e., students choose a FoL and work with others who have also chosen the topic.

The instructions, in the form of the ontology, are made available for the students (both in their online learning platform and on paper) and students are given a week after the first meeting to begin structuring their research plan and approach to the FoL and subsequent LBSD process. The groups then present their ideas and preliminary plans to the group. During this research plan session questions are asked and feedback is given by both the students' peers as well as lecturers and tutors. After this presentation session all other meetings take place during supervision times arranged by the students with the teachers and tutors. In the two month course students are required to meet with teachers and tutors at least twice for guidance.

The supervision sessions are designed to provide the groups with advice regarding means of approach towards investigating the FoLs as well as in terms of theory. The theoretical direction of this supervision exists on three levels: 1) relating to the course subject - life-based service design its philosophies and methodologies; 2) regarding the FoL in question, particularly in relation to issues of cognition and human-technology interaction (HTI); and 3) relating to design itself - students are required to investigate past and state-ofthe-art services to discover possibilities and any present flaws in these services. There are no limits to how many times groups can arrange supervision, however the average amount of meetings is three. Generally, the amount of supervision sessions also rests on the level of challenge presented by the FoL and design problem in focus.

The groups present their projects at the final seminar of the course. Presentations take place according to the structure of ontology instructions, being with an introduction to the FoL stating simple facts about the group and then moving into previous scientific research regarding the FoL and specific everyday problems relating to this group of people. More previous research (if any) is presented regarding attempts to solve this problem. Then the students' own empirical component is explained. The empirical component consists of data collection from people experiencing this FoL via methods ranging from ethnography, to interviews and questionnaires, and even experiments in some cases. Based on the results of the empirical FoL material, the service design concept is either formulated or modified. The important aspect for students to remember in this process is that the research is not about discovering how to fit services into people's lives. Instead, it is about discovering how the services would naturally fit into their everyday lives.

The groups present their findings and following these they outline either the service design concept developed as a consequence of the research, or prototypes. In some cases groups have also managed to not only present prototypes, but also second or third iterations which have been influenced by 
user or usability studies with people from the FoLs in question. Approximately one month after the completion of the course, students are required to submit reports of the project and design process. There are no set page requirements for this, however on average groups submit around 25 page reports, some even 50 pages - depending on the design challenge and level of motivation.

\section{OUTCOMES OF THE COURSE}

Although LBSD is offered as a stand-alone course, its philosophies and the LBD methodology are present throughout the Cognitive Science Master's degree program. Therefore, continuation of projects initiated during the course is encouraged and supported. Since 2013, 49 students have taken part in the course. Of these, 24 were female and 25 were male. This equal representation of gender is already an achievement given that the course is held in the Faculty of Information Technology, which is dominated by male students. The age distribution of students is broad, the youngest being 23 years of age and the oldest being 58 - the average age being 31 years of age.

Besides the cognitive science students, students undertaking the course also come from disciplines such as information systems, computer science and software engineering. Students also come from diverse backgrounds, many already having vast professional experience either in the fields in question or in other fields. For this reason LBSD course and the LBD methodology, in light of the constructivist approach to learning that PBL affords, is highly advantageous for these types of student groups.

Since beginning the course 17 projects have been undertaken. The FoLs have included: young children (childcare and pre-school) learning about nature; families with children (young children and youth); foreign students seeking accommodation; people with memory impairment (institutionalized elderly and young elderly with early diagnosis); healthcare professionals providing services for elderly still living at home; tertiary students with Asperger's syndrome; tertiary students with vision impairment; foreign students with vision impairment; and organizational leaders seeking innovation management systems to name some.

The types of service concept designs which have derived from the studies have included: scheduling services; social media directly for the FoL in question; accommodation matchmaking; information systems enabling more fluent home healthcare options; affective toys; daily audio assistants; innovation management services; and augmented reality for educational application. Of these 17 projects, seven $(41 \%)$ have continued after course completion. Some of these have been continued in other subjects offered by cognitive science such as User Research, Usability Analysis and Interaction Design. Four of the projects have been used as platforms for service business ideas, and two (an innovation management service and an augmented reality educational application) have received national innovation funding to be developed further on a much larger scale. These funded projects in themselves are substantial achievements.

Numerous advantages have been noticed in adapting LBD as an educational approach and philosophy in the cognitive science program. Here is a list of the strengths of the method:

- It provides a fun and active introduction into human cognition placing real life situations at the foreground

- Theory is readily integrated into practical problems both relating to the FoLs as well as design issues

- Learning takes place on three levels: 1) LBD methodology and theory; 2) FoL familiarization; and 3) design theory, practice and state-of-the-art innovations

- Contextual, social, psychological and physical aspects affecting HTI are emphasized as central figures rather than the designs themselves

- Through consistency and support among staff (and faculty) LBSD course provides continuation to projects, supporting deeper learning

- Continuation and possibilities for greater achievements provide students with motivation for learning

During the course's history there has, however, been criticism towards this methodology, which can be seen as a side-effect of this independent, or self-guided (while in a group) constructivist approach. This relates to the minimal amount of lectures, an argument which contradicts the problems seen in the work of Mills and Treagust [22] who note the prominence of pen and paper engineering education, which sacrifices student motivation and engagement for the safety of traditional teaching implementation. Another problem rests in the group work itself and the distribution of responsibility between group members. Students have complained about final grades in light of some group members not producing as much as others.

Despite these short-comings, as the result of the consistency, adaptability and multiplicity of the course method, strengths rest not only in its effectiveness in relation to student learning, but its ability to construct firm collaborative relationships. These relationships occur within the student groups, between students, teachers and tutors, and between the teaching staff themselves. There is the atmosphere of constructing something larger in terms of understanding users, and possibly creating new innovations which will improve life quality. On this note, relationships between students and people in the FoLs themselves are also forged. 


\section{LBSD COURSE APPROACH AS EXPLICIT PBL REINFORCEMENT}

There are many overlaps between PBL and the LBSD course approach. However, as cited in relation to the comparison between PBL and project-based learning, LBSD is not only driven towards students acquiring information, it also requires them to apply it. Thus, through beginning with the empirical - FoLs - moving soon to the theoretical (both regarding the FoLs as well as design), and then back into practical application within the concept design (see Figure 3), LBSD can be seen as a combination of the two, plus more.

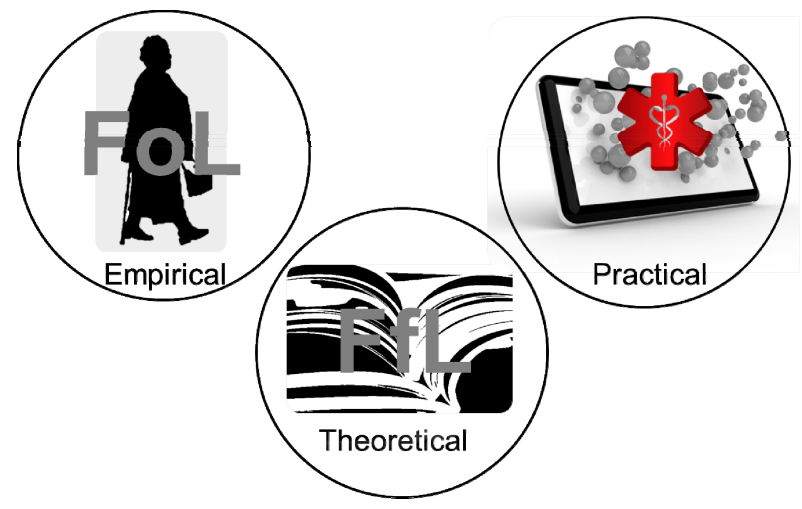

Fig. 3. LBSD methodological learning

The more comes into question when considering the holistic nature in which the LBSD course is delivered. That is, the projects that begin in the LBSD course do not simply stop there. If the students desire, they may continue their research and development projects throughout the cognitive science program, building on their knowledge and expertise of issues relating to cognition and HTI in relation to the FoL, and strengthening their skills as service designers. This may be continued into thesis work, and as seen in several of the projects so far, may even go on to develop into business ideas and/or attract national innovation project funding.

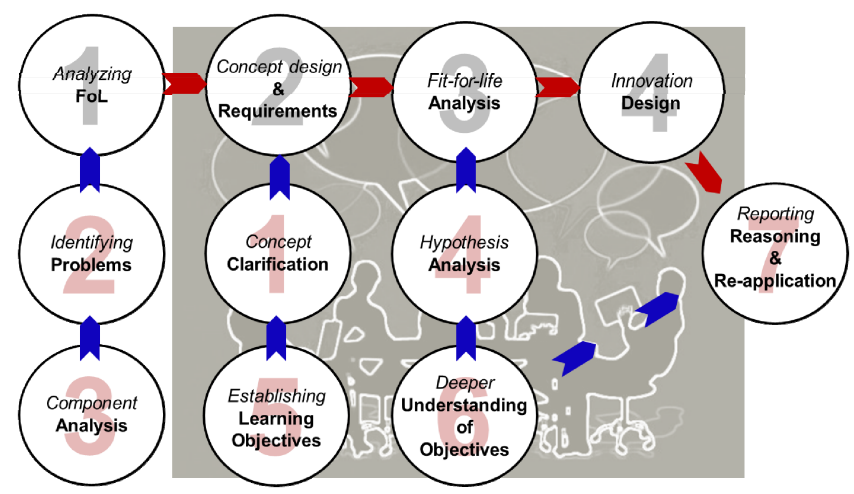

Fig. 4. Relationship between LBSD and PBL according to Schmidt's [20] 7steps
There are four major stages in the LBD ontologies that students follow as a part of the LBSD course. While there are only four, they are intensive as three of the stages comprise at least six of the seven PBL steps Schmidt [20] outlines (see Figure 4). The LBD stages and the seven PBL steps are related in a non-linear way. As seen in the diagram, it may be noted that stage one, Analyzing FoL, entails the identification of problems and component analysis. Stage two, Concept design and requirements, includes the clarification of concepts and also the establishment of learning objectives (three fold LBD, FoL and design possibilities). Stage three, FfL analysis, comprises hypothesis analysis - are the means of rationalizing the FoL and their needs and desires accurate? It additionally requires that students dig deeper and strengthen their understanding of the learning goals and objectives. Stage four, the innovation design component resembles part of the concretization phase of project-learning. Subsequently, at the end of the LBSD course, groups report their projects and reason their findings. Finally, there is the hope with this methodology that the learning does not end there, but continues with re-application and continual research - keeping abreast of the developments and changes which are occurring in our rapidly moving societies.

\section{CONCLUSION}

This paper has focused on explaining the application of a design methodology, Life-based design, for the purposes of gaining a deeper understanding of people and their daily lives in the fields of service and technology development. As a point of departure, the paper has used PBL as an anchor in order to demonstrate the stages and components of the learning process when using a methodology such as this in a cognitive science program. This paper has highlighted criticism towards "chalk and talk" modes of teaching in engineering education, and emphasized the mode of learning in the LBSD course as that which is guided by real life. Design issues and problems are contextualized in social, physical, psychological, economic and even information (access to) factors. The contextualization forms motivation for delving into the theoretical, to find out how the FoL has been characterized, what the typical problems are, what has been done, and where the gaps lie for what can be done. This knowledge is then applied to the development of concept service designs, and even in some cases, prototypes and working prototypes.

The UCD process is iterative, and by following the LBD method, people from relevant FoLs not only inform the concept design but test the concepts and prototypes in terms of usability, usefulness and overall desirability of the products. Questions asked within the LBD methodological process do not purely pertain to whether or not the design would be useful or usable. Instead, the questions concern how the designs, technologies and services in general fit into the lives of these people, and whether or not, the services and technologies to be developed will improve their life quality.

Pressure is on educators to equip students with the much discussed " $21^{\text {st }}$ century skills". While qualities such as self- 
direction, communication and collaborative team skills have been emphasized, there is still something more that we as educators and (educational) designers may hope for. The term "designing for happiness" is not unfamiliar to developers of the LBD methodology [6] [7] [8]. And, given the versatile and uncertain conditions the students as future designers and engineers face, designing for happiness for people of all walks of life in diverse situations seems a noble goal strive for.

\section{ACKNOWLEDGMENT}

We would like to thank the University of Jyväskylä for the opportunity to push our exploration of pedagogical methodologies in cognitive science, design and engineering, as well as for the opportunity to write this paper. Many thanks also goes to VTT for supporting this research.

\section{REFERENCES}

[1] G. Eason, B. Noble, and I.N. Sneddon, "On certain integrals of Lipschitz-Hankel type involving products of Bessel functions," Phil. Trans. Roy. Soc. London, vol. A247, pp. 529-551, April 1955. (references)

[2] W. McComas, "21st-century skills," in The Language of Science Education - An Expanded Glossary of Key Terms and Concepts in Science Teaching and Learning, Fayettevill, AR: Sense Publishers, 2014, p.1.

[3] B. Trilling, and C. Fadel, 21st century skills: Learning for life in our times, Hoboken, NJ: John Wiley \& Sons, 2009.

[4] J. Voogt, and N. Roblin, "21st century skills," Discussienota, Zoetermeer: Kennisnet, 2010.

[5] P. Baltes, "The aging mind: Potential and limits," The Gerontologist, vol. 33, issue 5, pp. 580-594, 1993.

[6] P. Baltes, U. Lindenberger, and U. Staudinger, Life span theory in developmental psychology. Hoboken, NJ: John Wiley \& Sons, 1998.

[7] J. Leikas, Life-Based Design - A Holistic Approach to Designing Human-Technology Interaction, VTT Publications 726, Helsinki: Edita Prima, 2009.

[8] P. Saariluoma, and J. Leikas, "Life-based design - An approach to design for life," Global Journal of Management and Business Research GJMBR, vol. 10, issue 5, 2010, pp. 17-23.

[9] J. Leikas, P. Saariluoma, J. Heinilä, and M. Ylikauppila, "A methodological model for Life-Based Design." International Review of Social Sciences and Humanities (IRSSH), vol. 4, issue 2, 2013, pp. 118136.

[10] B. Crandall, G. Klein, and R. Hoffman, Working mindes: A practitioner's guide to cognitive task analysis, Cambridge, MA: MIT Press.

[11] W. Karwowski, The discipline of ergonomics and human factors, in G. Salvendy, Ed., Handbook of Ergonomics, Hoboken, NJ: John Wiley \& Sons, 2006

[12] J. Nielsen, Usability Engineering, San Diego, CA: Academic Press, 1993.

[13] J. Noyes, Designing for Humans, New York, NY: Taylor \& Francis, 2001.

[14] M. Rosson, and J. Carroll, Usability Engineering: Scenario-Based Development of Human Computer Interaction, San Francisco, CA: Morgan-Kaufmann, 2002,

[15] C. Vickens, and J. Hollands, Engineering Psychology and Human Performance, Upper Saddler River, NJ: Prentice-Hall, 2000.
[16] A. Neville, "Problem-based learning and medical education forty years on. A review of its effects on knowledge and clinical performance," Medical principles and practice: international journal of the Kuwait University, Health Science Centre, vol. 18, issue 1, 2008, pp 1-9.

[17] H. Barrows, Problem-based learning applied to medical education Springfield. Carbondale, Southern Illinois University School of Medicine, 2000

[18] H. Walton, and M. Matthews, Essentials of problem-based learning, Med Educ, vol. 23, 1989, pp. 542-558.

[19] D. Vernon, and R. Blake, Does problem-based learning work? A metaanalysis of evaluative research. Acad Med, vol. 68, 1993, pp. 550-563.

[20] H. Schmidt, Problem-based learning: Rationale and description. Med Educ, vol. 17, 1983, pp. 11-16.

[21] G.R. Norman, and H. Schmidt, The psychological basis of problem based learning: A review of the evidence. Acad Med, vol. 67, 1992, pp. $557-565$.

[22] P. Kirschner, J. Sweller, and R. Clark, "Why minimal guidance during instruction does not work: An analysis of the failure of constructivist, discovery, problem-based, experiential, and inquiry-based teaching. Educ. Psychol., vol. 41, 2006, pp. 75-86.

[23] J. Mills, and D. Treagust, "Engineering education-Is problem-based or project-based learning the answer?," Australasian J. Eng. Educ., vol. 3.2, 2003, pp. 2-16.

[24] R. Henshaw, "Desirable attributes for professional engineers," in J. Agnew, and C. Creswell, Eds., Broadening horizons of engineering education, 3rd Annual conference of Australasian Association for Engineering Education, 15-18 December 1991, University of Adelaide, 1991, pp. 199-204.

[25] J. Lang, S. Cruise, F. McVey, and J. McMasters, "Industry expectations of new engineers: A survey to assist curriculum designers," J. Eng. Educ. vol. 88, issue 1, 1999, pp. 43-51.

[26] H. Beetham, and R. Sharpe, R., Eds., Rethinking pedagogy for a digital age: Designing for 21st century learning, London: Routledge, 2013.

[27] D. Woods, R. Felder, A. Rugarcia, and J. Stice, "The future of engineering education III. Developing critical skills," Chem. Eng. Educ., vol. 34, issue 2, 2000, p. 108-117.

[28] D. Woods, A. Hrymak, R. Marshall, P. Wood, C. Crowe, T. Hoffman, J. Wright, P. Taylor, K. Woodhouse, and C. Bouchard, "Developing problem solving skills: The McMaster problem solving program," J. Eng. Educ., vol. 86, issue 2, 1997, pp. 75-91.

[29] C. Crouch, and J. Pearce, J., Doing research in design, Oxford: Berg, 2012.

[30] J. Perrenet, P. Bouhuijs, and J. Smits, "The suitability of problem-based learning for engineering education: Theory and practice," Teaching in higher education, vol. 5, issue 3, 2000, pp. 345-358.

[31] H. Bouma, J. Fozard, D. Bouwhuis, and V. Taipale, "Gerontechnology in perspective," Gerontechnology, vol. 6, issue 4, 2007, pp. 190-216.

[32] H. Bouma, and J. Graafmans, J. Eds., Gerontechnology, vol. 3, Amsterdam: IOS Press, 1992.

[33] L. Fozard, J. Rietsema, H. Bouma, J. Graafmans, "Gerontechnology: Creating enabling environments for the challenges and opportunities of aging," Educational Gerontology, vol. 26, issue 4, 2000, pp. 331-344.

[34] G. Van Galen, "Handwriting: Issues for a psychomotor theory," Human movement science, vol. 10, issue 2, 1991, pp. 165-191.

[35] G. O'Connor, "Market learning and radical innovation: A cross case comparison of eight radical innovation projects," J. prod. innov. man., vol. 15, issue 2, 1998, pp. 151-166.

[36] J. Leikas, and V. Ikonen, "Life-based design to ensure that technology is fit for life," in M. Isomursu, M. Toivonen, M. Kokkala, and P. Pussinen Eds., Highlights in service research, VTT Research Highlights, vol. 6, 2013, pp. 23-29. 